\title{
Design and Development of Wireless power transfer system for Intracranial pressure monitoring devices
}

\author{
Duvvuru Sravya ${ }^{1, *}$, Phaneendra Babu Bobba ${ }^{1}$ and Avni Majawadia Jain ${ }^{2}$ \\ ${ }^{1}$ Department of Electrical Engineering, Gokaraju Rangaraju Institute of Engineering and Technology, Telangana, India \\ ${ }^{2}$ Shri G.S. Institute of Science and Technology, Indore
}

\begin{abstract}
Wireless power transfer was today used for many applications regarding high power and low power transmission. Biomedical applications are lower power applications where WPT occurs between the power coils, one of which will be implanted in the body whereas other will be outside the body as Transmitting coil. Here the paper refers to the Wireless power transfer system to Intracranial Pressure monitoring devices. The proposed system operates at $180 \mathrm{KHz}$ frequency for both Magnetic resonant coil design and WPT system analysis. The Mixed Resonance scheme at receiving side will be used as compensation topology for compatibility in Power delivered to load. Analysis and comparison for different coil structures are also verified for best suitable configuration for efficient power transfer.
\end{abstract}

\section{Introduction}

Intracranial pressure is the pressure present in craniospinal compartment, which is closed consisting of fixed volume of neural tissues, blood and cerebrospinal fluid. It is measured in $\mathrm{mm} \mathrm{Hg}$. For a normal person value of ICP ranges from 5-15 $\mathrm{mm} \mathrm{Hg}$.

When amount of fluid surrounding the brain increases the value of ICP increases which is due to certain reasons like bleeding in the brain, tumor, stroke, aneurysm, high blood pressure or brain infection. Increased ICP results in serious complications to the person. so, ICP monitoring devices are used for continuous monitoring of ICP levels for patient suffering from brain diseases. Some diseases due to ICP are likely Hydrocephalus, CSF Leak and Pseudo tumor cerebri[2].

ICP monitoring is done either by invasive or noninvasive techniques. Invasive methods of ICP monitoring are ventriculostomy and microtransucers. Of the two invasive techniques mentioned ventriculostomy is widely used. However invasive method has a little disadvantage of hemorrhage and infection. Ventriculoperational Shunt (Catheter) is the surgical treatment procedure of Hydrocephalus, which is used for diversion of excess CSF in the ventricles of brain $[1,3]$.

So ICP should be regularly monitored and treated accordingly. Sensors and monitoring systems will be powered by conventional battery[4]. So wireless power transfer system can be used for charging the battery.
In the following sections of the paper, WPT approach for ICP monitoring device is discussed.

In section 2, compensation topology for the WPT system of ICP monitoring device is proposed. In section 3 power coils for the system is designed in different layer configurations in different structures is discussed. In section 4 Analysis of the proposed system was discussed. Finally the Conclusions were drawn based on the simulated model.

\section{Proposed System}

In the proposed system the compensation topology used for tuning of transmitting and receiving is, basic series compensation at the transmitting side and mixed resonance scheme at the receiving side.

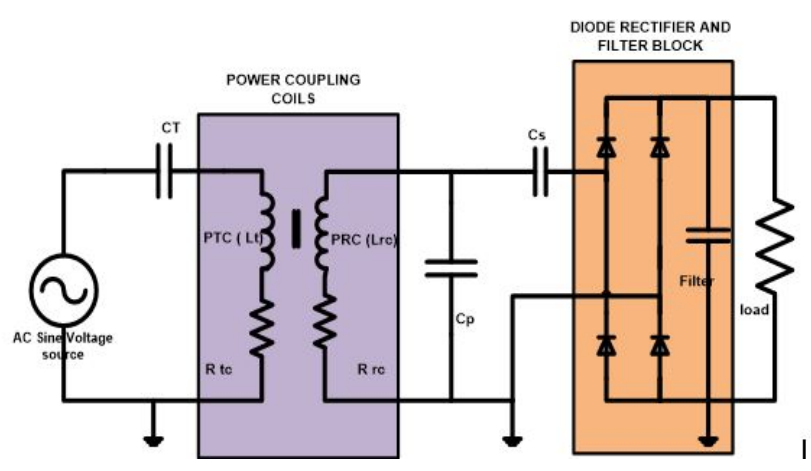

Fig. 1. WPT System Circuit with Compensation Topology of Power coils. 
Table.1. Comparison of Coil structures and Magnetic Flux Distribution of each topology

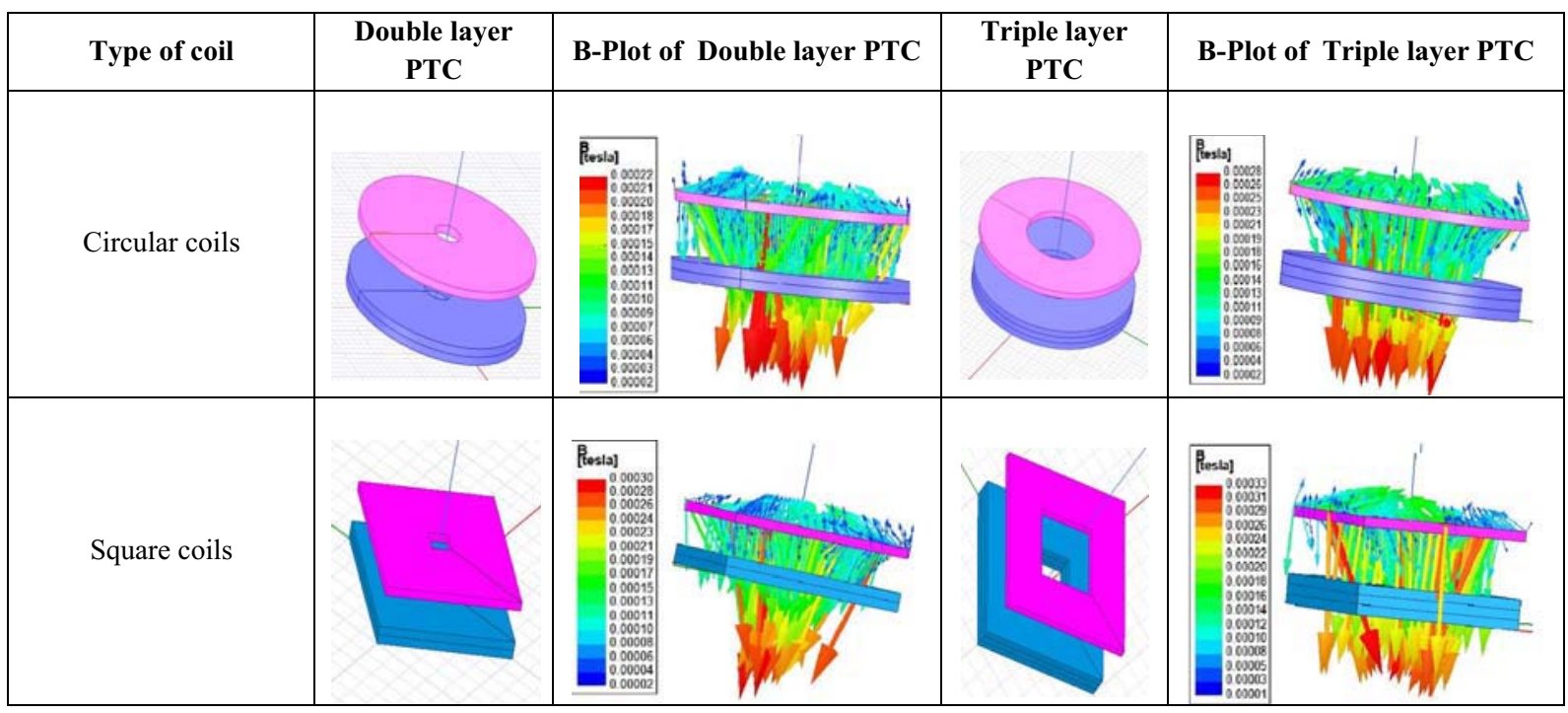

Table.2. Comparison of Specifications and Simulated Results of each topology

\begin{tabular}{|c|c|c|c|c|c|c|c|c|c|}
\hline \multirow{2}{*}{$\begin{array}{c}\text { Section of } \\
\text { Comparison }\end{array}$} & \multirow{2}{*}{$\begin{array}{l}\text { Parameters } \\
\text { compared }\end{array}$} & \multicolumn{2}{|c|}{$\begin{array}{l}\text { Circular Double } \\
\text { Layer PTC }\end{array}$} & \multicolumn{2}{|c|}{$\begin{array}{l}\text { Squared Double } \\
\text { Layer PTC }\end{array}$} & \multicolumn{2}{|c|}{$\begin{array}{c}\text { Circular Triple } \\
\text { Layer PTC }\end{array}$} & \multicolumn{2}{|c|}{$\begin{array}{l}\text { Squared Triple } \\
\text { Layer PTC }\end{array}$} \\
\hline & & PTC & PRC & PTC & PRC & PTC & PRC & PTC & PRC \\
\hline \multirow[t]{3}{*}{$\begin{array}{c}\text { Physical } \\
\text { Parameters } \\
\end{array}$} & Height $\mathrm{h}(\mathrm{mm})$ & 1.77 & 1.77 & 1.77 & 1.77 & 1.77 & 1.77 & 1.77 & 1.77 \\
\hline & $\begin{array}{l}\text { Outer and inner } \\
\text { radius }(\mathrm{mm})\end{array}$ & $\begin{array}{c}25 \\
3.75\end{array}$ & $\begin{array}{c}25 \\
3.75\end{array}$ & $\begin{array}{c}25 \\
3.75\end{array}$ & $\begin{array}{c}25 \\
3.75\end{array}$ & $\begin{array}{c}25, \\
10.84\end{array}$ & $\begin{array}{c}25 \\
10.84\end{array}$ & $\begin{array}{c}25 \\
10.84\end{array}$ & $\begin{array}{c}25, \\
10.84\end{array}$ \\
\hline & No of Turns N & 12 & 12 & 12 & 12 & 8 & 8 & 8 & 8 \\
\hline \multicolumn{2}{|c|}{ Distance between power coils d(mm) } & 10 & 10 & 10 & 10 & 10 & 10 & 10 & 10 \\
\hline \multirow[t]{2}{*}{$\begin{array}{c}\text { Electrical } \\
\text { Parameters } \\
\end{array}$} & Current I(A) & 3.3 & 1.7 & 3.3 & 1.7 & 3.3 & 1.7 & 3.3 & 1.7 \\
\hline & Frequency $\mathrm{f}(\mathrm{KHz})$ & 180 & 180 & 180 & 180 & 180 & 180 & 180 & 180 \\
\hline \multirow[t]{2}{*}{$\begin{array}{c}\text { Output } \\
\text { Parameters } \\
\text { obtained }\end{array}$} & $\begin{array}{l}\text { Inductance of total } \\
\text { coils } \mathrm{L}(\mu \mathrm{H})\end{array}$ & 8.801 & 3.21 & 9.35 & 2.61 & 13.59 & 2.407 & 12.28 & 2.09 \\
\hline & $\begin{array}{l}\text { Coefficient of } \\
\text { coupling (k) }\end{array}$ & \multicolumn{2}{|c|}{0.2987} & \multicolumn{2}{|c|}{0.247} & \multicolumn{2}{|c|}{0.34} & \multicolumn{2}{|c|}{0.251} \\
\hline
\end{tabular}

Mixed resonance scheme is used as it delivers efficient amount of power to receiver unit in comparison to series and parallel resonance schemes. The proposed system is operated at $180 \mathrm{KHz}$ frequency and load resistance is considered as $6.5 \Omega$. The following equations are the basic formule used for analyzing the proposed system[5,6]:

Resonating Frequency of the system

$$
f=\frac{1}{2 \pi \sqrt{L t C t}}=\frac{1}{2 \pi \sqrt{\operatorname{LrCCrC}}} \ldots \ldots
$$

Coupling coefficient

$$
k=\frac{M}{\sqrt{L t L r C}}
$$

Compensation components can be calculated by using the following formulae to tune the power coils at a particular frequency[5].

The parallel capacitance $(\mathrm{Cp})$ in the receiver side 


$$
C p=\frac{\sqrt{R r c^{2}+w^{2} L r C^{2}}-R i}{w R l \sqrt{R r c^{2}+w^{2} L r c^{2}}}
$$

The Series Capacitance (Cs) of the Receiver coil

$$
C s=\frac{\left(1-w^{2} \operatorname{LrcC} p\right)^{2}+(\operatorname{RrcwCp})^{2}}{w^{2}\left[\operatorname{Lrc}\left(1-w^{2} \operatorname{LrCCp}\right)-\operatorname{Rr} C^{2} C p\right]}
$$

Where w represents the angular frequency of the system, Rrc represents the receiver resistance and $\mathrm{R} 1$ is Load resistance.

Table.3. Circuit model specifications of different layer PTC coils in circular and square coil structures

\begin{tabular}{|c|c|c|c|c|}
\hline Input and Compensation parameters & $\begin{array}{c}\text { Double layer } \\
\text { Circular PTC } \\
\text { coil }\end{array}$ & $\begin{array}{c}\text { Triple layer } \\
\text { Circular PTC } \\
\text { coil }\end{array}$ & $\begin{array}{c}\text { Double layer } \\
\text { Square PTC } \\
\text { coil }\end{array}$ & $\begin{array}{c}\text { Triple layer } \\
\text { Square PTC } \\
\text { coil }\end{array}$ \\
\hline Input Voltage(V) & 20 & 20 & 20 & 20 \\
\hline Input Frequency(Hz) & 180000 & 180000 & 180000 & 180000 \\
\hline PTC Inductance $(H)$ & $8.81 \mathrm{e}-6$ & $13.59 \mathrm{e}-6$ & $9.35 \mathrm{e}-6$ & $12.28 \mathrm{e}-6$ \\
\hline PRC Inductance(H) & $3.21 \mathrm{e}-6$ & $2.407 \mathrm{e}-6$ & $2.61 \mathrm{e}-6$ & $2.09 \mathrm{e}-6$ \\
\hline Input Resistance $(\boldsymbol{\Omega})$ & 7.05 & 7.05 & 7.05 & 7.05 \\
\hline Coupling coefficient & 0.2987 & 0.34 & 0.247 & 0.251 \\
\hline Load Resistance $(\boldsymbol{\Omega})$ & 6.5 & 6.5 & 6.5 & 6.5 \\
\hline Transmitting Capacitance $(\mathrm{F})$ & $88.8 \mathrm{e}-8$ & $57.5 \mathrm{e}-8$ & $83.6 \mathrm{e}-8$ & $63.7 \mathrm{e}-8$ \\
\hline Parallel receiving coil capacitance(F) & $245 \mathrm{e}-12$ & $190 \mathrm{e}-12$ & $203 \mathrm{e}-12$ & $171 \mathrm{e}-12$ \\
\hline Series receiving coil capacitance(F) & $0.244 \mathrm{e}-6$ & $0.327 \mathrm{e}-6$ & $0.301 \mathrm{e}-6$ & $0.375 \mathrm{e}-6$ \\
\hline
\end{tabular}

\section{Designing of Power Transmitting and Power Receiving coils}

Transmitting and receiving coils of ICP are investigated in double and triple layers of circular and square structure of power transmitting coil (PTC) and single layer circular and square structure for receiving coil unit.

For double layered structure of PTC coil is designed for 24 turns with 12 turns per layer and for triple layer it is designed for 8 turns per layer and single layer of PRC coil number of turns is 12 turns for double layer and for triple layer its is designed for 8 turns. The system is operated at $180 \mathrm{KHz}$.

The design specifications of the coils and the corresponding output results of simulation inductances of coils and coefficient of coupling are listed in table 2 .

From the results obtained from simulation of coils in different coil configurations it has been observed that,

$\checkmark$ For the same shape of coils with increase in number of layers, the inductance values of PTC is increased for triple layer configuration whereas inductance value is decreased in PRC for triple layer when compared to double layer configuration. The coefficient of coupling is higher for triple layer configuration than double layer.

$\checkmark$ For the same number of layers when different coil structures are compared it is observed the circular coil has better coefficient of coupling in comparison with square coil structure and the value of inductance in receiving coil is lower in square coil structure than circular coil structure.

\section{Analysis of Proposed Network for WPT system}

For the same shape of coils with increase in number of layers inductance values of power transmitting coils is increased for triple layer configuration whereas inductance value is decreased in receiving coil for triple layer when compared to double layer configuration.

As input voltage given to all models are same but the performance varies based on the compensation parameters, coefficient of coupling between the coils and the Inductances obtained by simulation. The battery nominal voltage was $3.1-3.3 \mathrm{~V}$.

The potential range of battery as per Charging and discharging cycles was treated was $1.5-4.5 \mathrm{~V}$. The voltage output obtained at the load was within the limited range so the model can be used for practical purpose. The Triple layer circular model Load voltage was better comparatively as per Table 4 .

Table.4. Comparison of Simulated results of PDL and PTE of each coil configuration

\begin{tabular}{|c|c|c|c|c|}
\hline \multirow{4}{*}{ Quantity } & $\begin{array}{c}\text { Doubl } \\
\text { e } \\
\text { layer } \\
\text { Circul } \\
\text { ar }\end{array}$ & $\begin{array}{c}\text { Triple } \\
\text { layer } \\
\text { Circula } \\
\text { r PTC } \\
\text { PTC } \\
\text { coil }\end{array}$ & $\begin{array}{c}\text { Doubl } \\
\text { e layer } \\
\text { Squar } \\
\text { e PTC } \\
\text { coil }\end{array}$ & $\begin{array}{c}\text { Triple } \\
\text { layer } \\
\text { Squar } \\
\text { e PTC } \\
\text { coil }\end{array}$ \\
\hline Input Voltage & 19.92 & 19.92 & 19.92 & 19.92 \\
\hline
\end{tabular}




\begin{tabular}{|c|c|c|c|c|}
\hline$(\mathrm{V}) \mathrm{V}_{\mathrm{i}}$ & & & & \\
\hline $\begin{array}{c}\text { Input Current } \\
(\mathrm{A}) \mathrm{I}_{\mathrm{i}}\end{array}$ & 2.72 & 2.68 & 2.76 & 2.76 \\
\hline $\begin{array}{c}\text { Output } \\
\text { Voltage(V) } \mathrm{V}_{\mathrm{o}}\end{array}$ & 2.31 & 2.792 & 1.80 & 1.88 \\
\hline $\begin{array}{c}\text { Output Current } \\
(\mathrm{A}) \mathrm{I}_{\mathrm{o}}\end{array}$ & 0.355 & 0.429 & 0.278 & 0.289 \\
\hline Input Power & 27.07 & 26.69 & 27.48 & 27.52 \\
\hline
\end{tabular}

\begin{tabular}{|c|c|c|c|c|}
\hline $\mathrm{P}_{\text {in }}(\mathrm{W})$ & & & & \\
\hline $\begin{array}{c}\text { Output Power } \\
\mathrm{P}_{\mathrm{o}}(\mathrm{W})\end{array}$ & 0.820 & 1.198 & 0.503 & 0.543 \\
\hline Efficiency $\rceil \%$ & 3.03 & 4.49 & 1.82 & 1.97 \\
\hline
\end{tabular}

Table.5. Representation of Simulation resulted Waveforms of each coil configuration

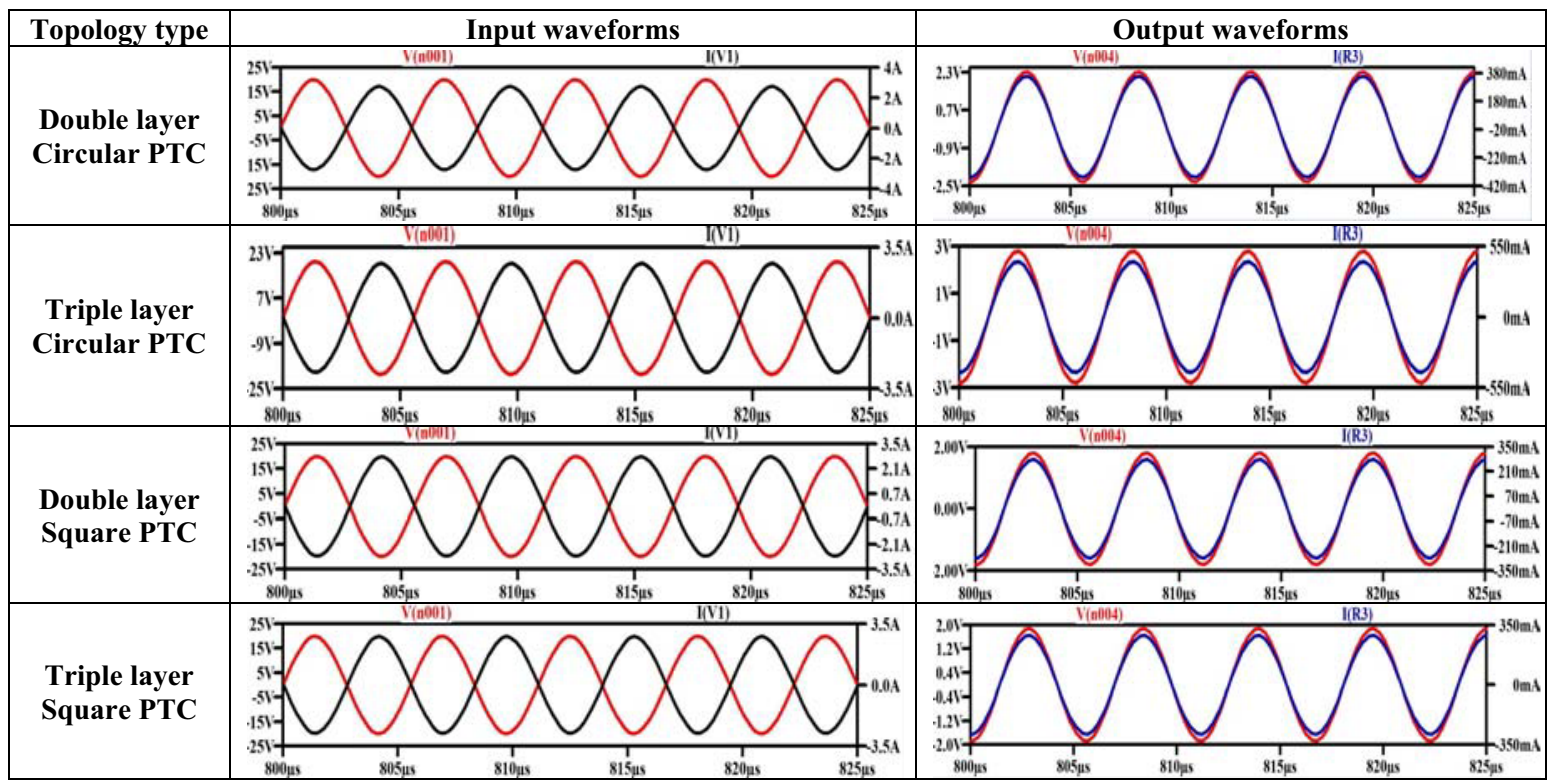

The Power delivered to the load required was around $766 \mathrm{~mW}$ and the obtained Power which is delivered to the load was good for Circular models as they are customized due to their easy and well suited size and structure for better alignment between the coils and easy design.The Power Efficiency was also more in Triple layer Circular model as $4.49 \%$ and the least efficient model as per the results was Double layer Square model. Finally based on all the simulations as per design and analysis the well suited type of topology was conventional Circular Double layer PTC with PRC model.

\section{Conclusions}

In the above proposed system of ICP monitoring devices the distance between coils are $10 \mathrm{~mm}$ considered for all the models with operating frequency of $180 \mathrm{KHz}$ where power output required as $500 \mathrm{~mW}$ to $900 \mathrm{~mW}$ and we obtained on an average of $766 \mathrm{~mW}$ for all the models based on our component requirement we can select the model of design required. Worst case obtained output power has an efficiency of $1.82 \%$ as per the least performance of the designed square model. Conventional circular coil models here double layered PTC model were best suited for practical hardware based on the performance levels in all aspects.

\section{References}

1. Smith, T.F., Waterman, M.S.: J. Mol. Biol. 147, 195 (1981)

2. May, P., Ehrlich, H.C., Steinke, T.: Nagel, W.E., Walter, W.V., Lehner, W. (eds.) Euro-Par. LNCS, 4128,1148 (2006)

3. Foster, I., Kesselman, C.: The Grid: Morgan Kaufmann, San Francisco (1999)

4. B. J. Varghese, P. B. Bobba and M. Kavitha, 2016 IEEE 7th Power India International Conference (PIICON), 2016, pp. 1-6

5. S. Seshadri, M. Kavitha and P. B. Bobba, 2018 International Conference on Power, Instrumentation, Control and Computing (PICC), 2018, pp. 1-6

6. B. J. Varghese and P. B. Bobba, 2016 IEEE 1st International Conference on Power Electronics, Intelligent Control and Energy Systems (ICPEICES), 2016, pp. 1-5 